\title{
Anomalous Origin of the Left Coronary Artery from the Pulmonary Trunk. Clinical Features and Midterm Results after Surgical Treatment
}

\author{
Fernando Amaral, Julene S. Carvalho, João A. Granzotti, Elliot A. Shinebourne \\ Ribeirão Preto, SP - Brazil - London, England
}

\begin{abstract}
Objective - To report the authors' experience with the anomalous origin of the left coronary artery (AOLCA) from the pulmonary trunk, emphasizing preoperative data, surgical aspects and midterm results of the follow-up.

Methods - Retrospective analysis of 11 patients operated upon at the Royal Brompton Hospital from October, 84 to April, 97.

Results - Nine infants had heart failure $(H F)$ and two other children presented with dyspnea and chest pain. All had ECG changes. The echocardio-gram identified the anomalous origin of the coronary artery in 7 (64\%) patients and hemodynamic studies were performed in 7 patients. All infants were operated upon between the $2^{\text {nd }}$ and $10^{\text {th }}$ month of life. Six patients were treated with aortic reimplantation of the left coronary artery, whereas five were operated upon according to the Takeuchi technique. All patients are alive, with clear improvement of the ECG changes and ventricular function, as evaluated by echocardiography. Two patients operated upon according to the Takeuchi technique required additional surgery due to severe supravalvular pulmonary stenosis.
\end{abstract}

Conclusion - AOLCA is a rare disease. Most patients show early signs of severe HF associated with ECG findings. Surgical therapy must be instituted early in the disease, preferentially through aortic implantation of the anomalous coronary artery, with a high possibility of success. Shortly after surgery, clinical and ECG improvement, as well as normalization of left ventricular function, should be expected.

Key words: anomalous left coronary artery, Bland-WhiteGarland syndrome, left ventricular function

Hospital do Coração de Ribeirão Preto/Fundação Waldemar B. Pessoa, Royal Brompton Hospital-Londres e Faculdade de Medicina de Ribeirão Preto da USP Mailing adress: Fernando Amaral - FMRP - Av. Bandeirantes, 3900 - 14049-900 - Ribeirão Preto, SP - Brazil.
The anomalous origin of the left coronary artery (AOLCA) from the pulmonary trunk, is a well described, although rare, congenital anomaly, with an incidence of about one case for each 300,000 live births ${ }^{1}$. This condition is more often characterized by a single origin of the whole left coronary artery (LCA) from the posterolateral wall of the pulmonary trunk ${ }^{2}$. Patients suffering from this anomaly usually show findings consistent with heart failure in the first few months of life and their survival depends on early surgical management ${ }^{3,4}$. The currently used techniques for the correction of this anomaly include aortic implantation of LCA $^{5,6}$, as well as the construction of an intrapulmonary tunnel connected to the aortic wall ${ }^{7}$. Both techniques are performed under extracorporeal circulation. The objective of this report is to present our experience with this curious anomaly, with an emphasis on the clinical and surgical aspects, as well as to analyze the midterm results after surgical intervention.

\section{Methods}

Available records from 11 patients with AOLCA operated upon at the Royal Brompton Hospital, London, between October, 84 and April, 97 were retrospectively reviewed. Eight (73\%) patients were female. All clinical information was recorded. Electrocardiogram (ECG), chest $\mathrm{X}$-ray and echocardiogram were obtained from all patients before surgery. Seven patients underwent hemodynamic study. Among the nine infants, eight were operated upon between the $2^{\text {nd }}$ and $6^{\text {th }}$ month of life and one was operated upon in the $10^{\text {th }}$ month of life. Two other children were operated upon when they were 6 and 12 years old. The clinical and laboratory findings used in the analysis of the results were those obtained during the last outpatient visit. All patients survived the surgery. The postoperative follow-up time ranged from 3 months to 11 years (mean $=4.6$ years), and the patients' age at the time of the study ranged from 2 to 14 years $($ mean $=6.6$ years $)$. 


\section{Results}

Preoperative evaluation - The 11 patients studied were symptomatic: nine infants had heart failure; in eight of these, the diagnosis of heart failure was made between the $1^{\text {st }}$ and $3^{\text {rd }}$ months of life and in the remaining patients this diagnosis was made during the 5 th month of life. Two other children showed late clinical findings: one had chest pain, which started at three years of age and another six-year-old girl had dyspnea on exertion. Among the nine infants with heart failure, $5(55 \%)$ apparently had episodes of angina, charac-terized by crying episodes with diaphoresis and pallor, and $8(88 \%)$ showed a systolic murmur consistent with mitral regurgitation.

The electrocardiogram showed a mean QRS axis between $0^{\circ}$ and $-60^{\circ}$ in seven patients $(64 \%)$, a mean QRS axis between $+30^{\circ}$ and $+60^{\circ}$ in three patients $(27 \%)$ and, in one patient, this axis could not be determined. All patients with heart failure showed a pattern of ischemia/necrosis in precordial leads. A deep Q wave in lead AVL was noted in 10 (91\%) patients, and $9(82 \%)$ patients showed absence of Q wave in the lower leads (fig. 1).

The chest X-ray showed a normal cardiac silhouette in

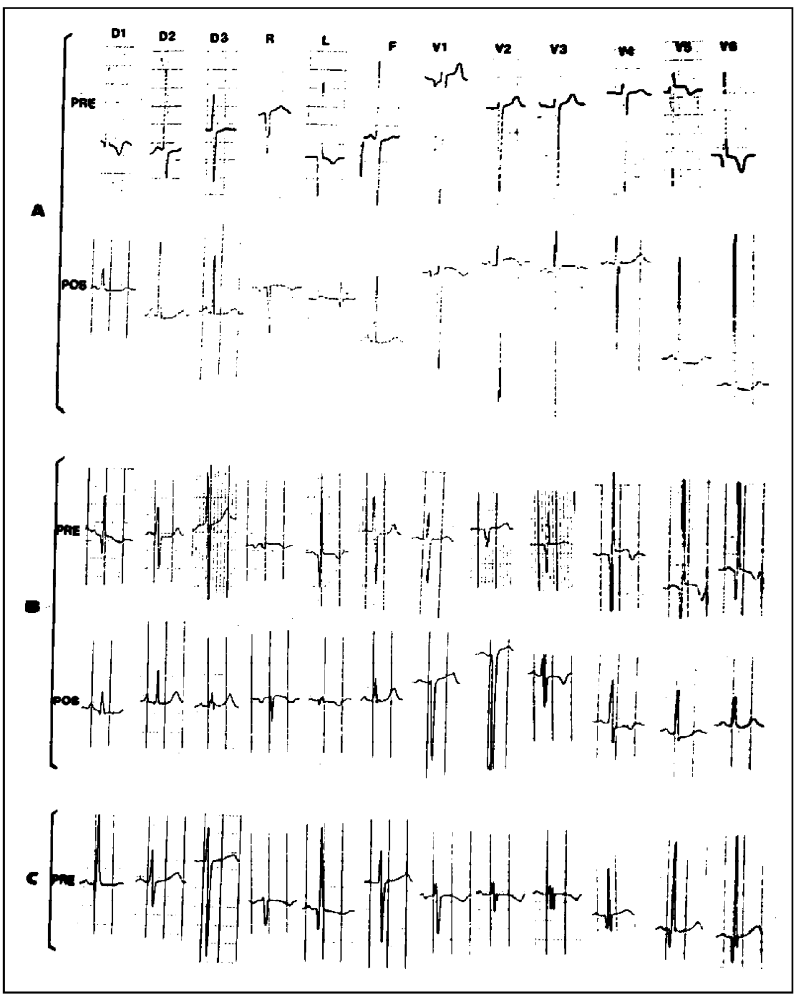

Fig. 1 - Electrocardiographic findings in AOLCA. A) Electrocardiogram before surgery (PRE), case \# 9: QRS at $0^{\circ}$, left chambers hypertrophy, deep Q wave in lead $A V L$ and significant ventricular repolarization abnormalities in the anterolateral wall. Six years after surgery (POS): persistent hypertrophy of the left chambers with improved ventricular repolarization; B) electrocardiogram before surgery (PRE), case \# 5: QRS at $-40^{\circ}$, deep Q wave in leads AVL and V2-V6, with abnormalities of ventricular repolarization. Four years after surgery (POS): improved ventricular repolarization and disappearance of the deep $\mathrm{Q}$ wave; $\mathrm{C}$ ) electrocardiogram before surgery in case \# 8: QRS at $-30^{\circ}$, left ventricular hypertrophy, deep Q wave in leads AVL, V5 and V6 and normal ventricular repolarization. the two oldest children, but, in all infants, an enlarged cardiac silhouette with variable degrees of pulmonary venous congestion was found (fig. 2).

In the echocardiogram, an anomalous LCA was made detected in 7 (64\%) patients. In 2 patients, the left ventricular function was normal, and in the 9 infants, it was made obviously abnormal. The ejection fraction, calculated in 4 patients, ranged from 0.21 to 0.31 .

A hemodynamic study was performed in 7 patients, either because they showed equivocal echocardiographic findings in the beginning of our experience or in order to confirm the diagnosis and obtain a better anatomical definition. The usual finding was a dilated right coronary artery (RCA) with a normal aortic origin that communicated with the LCA through collateral circulation. The anomalous artery draining into the pulmonary artery was documented during the late phase of injection into the RCA or through direct injection into the pulmonary artery (fig. 3) (tab. I).

Surgical therapy - The weight of the infants at the time of the surgery ranged from 3.4 to $5.0 \mathrm{~kg}$ (mean $=4.5 \mathrm{~kg}$ ), and the other remaining patients weighed 20 and $65 \mathrm{~kg}$. During surgery, it was noted that the LCA originated from the left posterior wall of the pulmonary artery in 6 patients, from the lateral wall in 2, and from the posterior wall in one. Two patients lacked a description of this origin. Six patients received an aortic implantation of the LCA, and 5 were operated upon according to the Takeuchi technique ${ }^{7}$. The latter consists of the creation of an aortopulmonary window that makes the communication of the anomalous LCA with the aorta. In 5 patients, the immediate postoperative period was uneventful. Four patients showed persistent signs of reduced cardiac output and two of these remained with their chests opened for 3-5 days. Two patients showed phrenic nerve palsy and another had atrial premature beats.

Late follow-up - All patients are alive. Among the 9 infants who showed heart failure before surgery, eight are asymptomatic, but one patient recently operated upon still shows symptoms and receives daily captopril. A heart murmur was found in 9 patients, including the 5 operated upon according to the Takeuchi technique.

The ECG showed marked improvement in the pattern of ischemia/necrosis in the infants. One patient had a normal ECG, but 10 still showed some abnormalities, such as persistence of Q wave in lead AVL, left ventricular hypertrophy, ST segment abnormalities and QRS axis deviation to the left. The deep Q wave in lead AVL observed in 10 patients before surgery returned to normal values in 5 patients (fig. 1).

The chest X-ray showed a normal cardiac silhouette in 7 patients, including the 6-year-old and 12-year-old patients with normal chest X-ray before surgery. In 4 patients, there was a reduction in the cardiac silhouette compared to the pre-operative aspect, although this parameter was still abnormal (fig. 2).

The 6 patients who received aortic implantation of the 


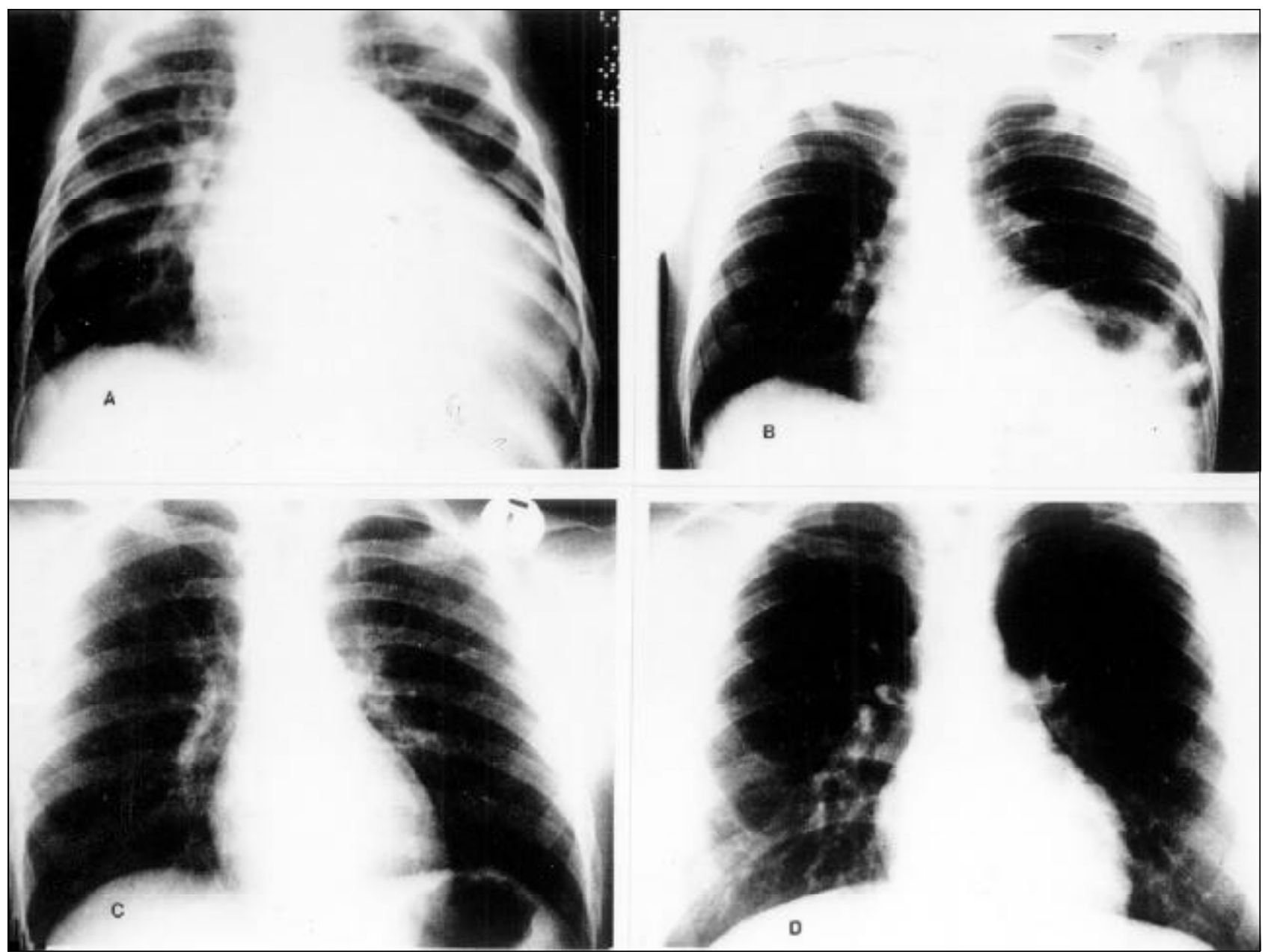

Fig. 2 - Chest X-ray in AOLCA. Case \# 4: A) Preoperative period: cardiomegaly; B) 22 months after surgery: improvement of the cardiomegaly, left phrenic nerve palsy; C) 5 years after surgery: normal radiological aspect; case \# 1: D) preoperative period: normal.

LCA did not require an additional surgery. Among the 5 patients operated upon according to Takeuchi technique, 2 were reoperated upon due to the development of severe supravalvular pulmonary stenosis $(80$ and $100 \mathrm{mmHg}$ gradients), and two other patients showed a $20 \mathrm{mmHg}$ gradient across the right ventricular (RV) outflow tract.

The normal origin of the LCA was documented in all the 10 patients who had a postoperative echocardiogram. Left ventricular function was normal in 9, and a recently operated upon patient still showed ventricular dysfunction.

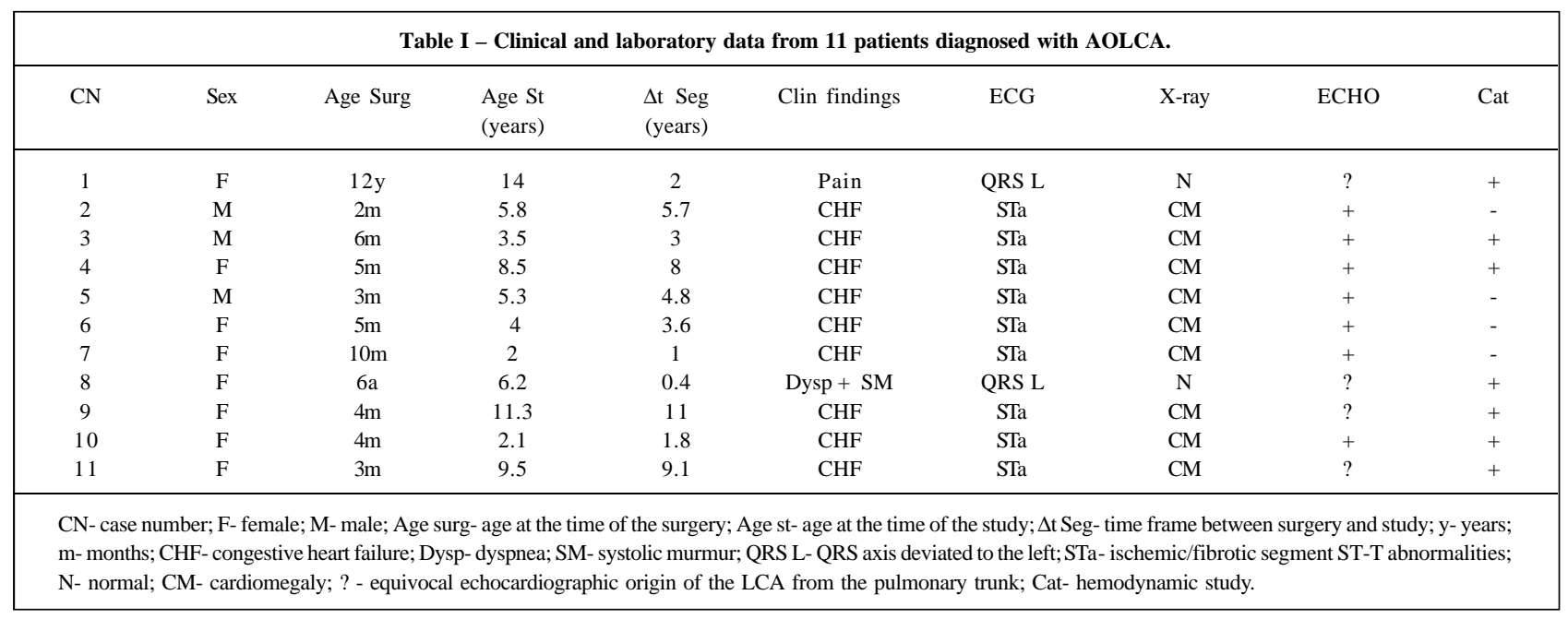


Four patients had slight supravalvular pulmonary stenosis (gradients between 12 and $20 \mathrm{mmHg}$ ), 2 of them after Takeuchi surgery. Mild mitral regurgitation was detected in 2 patients.

Five patients underwent another cardiac catheterization. All had a normal origin of LCA, and one had mild supravalvular pulmonary stenosis (fig. 3) (tab. II).

\section{Discussion}

The AOLCA from the pulmonary trunk is a well described, although rare, congenital anomaly in humans and, interestingly, in guinea pigs (hamster of Syrian origin) ${ }^{8}$. First, it must be noted that recent reports have presented equivocal information on historical data regarding this entity. Krause, in $1865^{9}$, and Brooks, in $1886^{10}$, were the first authors to report AOLCA. These reports, however, described an accessory coronary artery originating from a pulmonary artery and connected to 2 coronary arteries with a normal aortic origin. The first detailed description was given by Abrikosoff in $1911^{11}$. Later, Bland et al ${ }^{12}$ in 1933 , described a condition currently known as Bland-WhiteGarland syndrome, including in their study the angina-like findings, the important electrocardiographic abnormalities and also the presence of cardiomegaly related to the AOLCA.

Many reports have been published in the literature since then, describing mainly the surgical experience with this anomaly. In most cases, there is a single defect, although some studies show that this condition is occasionally associated with an atrial septal defect ${ }^{14}$, coarctation of the aorta ${ }^{15}$ and also with multiple anomalies ${ }^{16}$. In most patients, the LCA originates from the left posterior wall of the pulmonary trunk and, occasionally, variations of its trajectory may be surgically relevant ${ }^{17}$. The unique pathophysiology in this situation was precociously understood: after the decrease of the arterial pulmonary pressure during birth, the flow through the LCA becomes retrograde ${ }^{18}$ and distal coronary perfusion becomes dependent on an adequate collateral circulation between the RCA and the LCA. This situation usually does not preserve the myocardium, leading to variable degrees of necrosis ${ }^{19}$. These children usually show clinical findings of severe heart failure secondary to myocardial damage soon after the first month of life. Clinical findings resemble those of dilated cardiomyopathy and the diagnosis of AOLCA must be
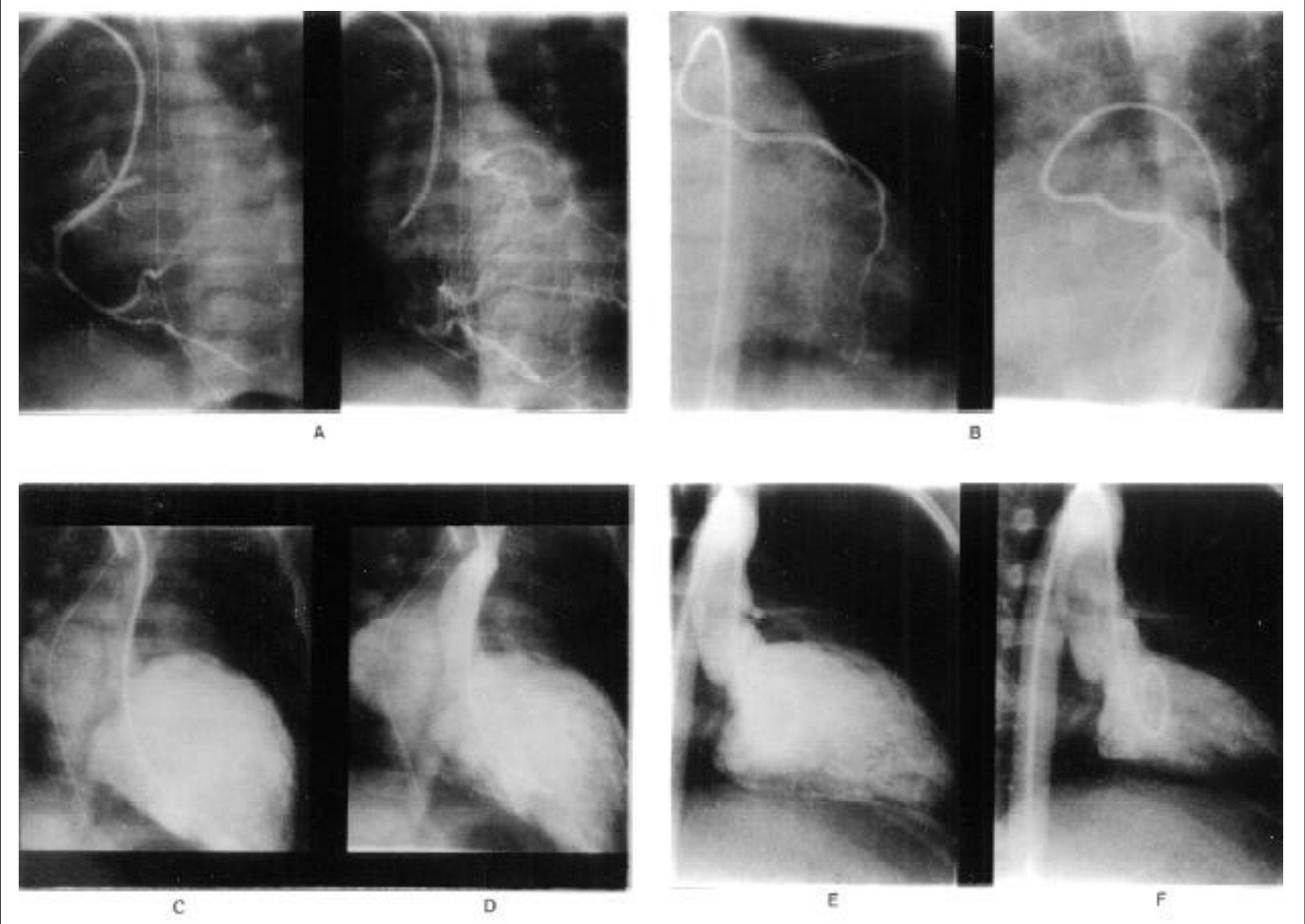

Fig. 3 - Cardiac catheterization in AOLCA. Case \# 9: A) a preoperative angiography of the right coronary artery: fistulous communication with the LCA and the pulmonary trunk. B) angiography of the LCA 4 months after surgery: normal trajectory; case \# 11: preoperative left ventriculography in diastole (C) and systole (D): increased volume and mitral regurgitation. Postoperative left ventriculography in diastole (E) and systole (F), 3 years after surgery: decreased final systolic volume without mitral regurgitation. 


\begin{tabular}{|c|c|c|c|c|c|c|}
\hline $\mathrm{CN}$ & Surgery & ECG & X-Ray & Echo & Cat & Reop \\
\hline 1 & Implantation & QRS L & $\mathrm{N}$ & $\mathrm{LCA} N+\mathrm{PS}$ & ---- & No \\
\hline 2 & Takeuchi & better & better & LCA N & LCA N + PS & Yes \\
\hline 3 & Implantation & better & better & LCA N & LCA N & No \\
\hline 4 & Takeuchi & better & $\mathrm{N}$ & LCA N + PS & ---- & No \\
\hline 5 & Takeuchi & $\mathrm{N}$ & $\mathrm{N}$ & $\mathrm{LCA} N+\mathrm{PS}$ & ---- & Yes \\
\hline 6 & Takeuchi & better & $\mathrm{N}$ & LCA N & ---- & No \\
\hline 7 & Implantation & better & better & LCA N & LCA N & No \\
\hline 8 & Implantation & QRS A & $\mathrm{N}$ & LCA N & ---- & No \\
\hline 9 & Implantation & better & $\mathrm{N}$ & LCA N & LCA N & No \\
\hline 10 & Takeuchi & better & better & LCA N + PS & ---- & No \\
\hline 11 & Implantation & better & $\mathrm{N}$ & ---- & LCA N & No \\
\hline
\end{tabular}

always remembered, especially in the presence of ischemic electrocardiographic abnormalities. Another extremely rare entity that must be remembered under these circunstances, since it can be operated upon, is the congenital atresia of the LCA's ostium. In this disease, clinical as well as electrocardiographic findings resemble those of the AOLCA ${ }^{20}$. The occurrence of severe myocardial ischemia due to AOLCA in the first days of life is exceptionally rare, but it has been reported ${ }^{21}$. Overall, anticongestive medication is used temporarily and, as soon as the diagnosis is confirmed, surgical correction is advised, in order to preserve the myocardium.

Since the first report of LCA ligature ${ }^{22}$ in 1959 , considerable advances have been made in the surgical techniques employed in these cases. Procedures such as myocardial revascularization and anastomoses of the LCA to the right or left subclavian artery have been employed, but their interest is currently considered exclusively historical ${ }^{23-26}$. The objective of modern heart surgery is to establish a system with 2 coronary arteries, either through the direct aortic implantation of the anomalous LCA, initially described by Neches in $1974^{5}$, or through the Takeuchi technique, described in 1979. In this ingenious procedure, a tunnel is constructed within the pulmonary artery in order to allow the communication of the LCA with the aorta through an aortopulmonary window ${ }^{7}$. Overall, the worldwide experience in the treatment of this anomaly is encouraging. Lambert et $\mathrm{al}^{27}$ described the midterm results in 39 cases. There were 5 deaths during hospitalization, no late deaths, and abnormal contractility of the ventricular wall was observed in $39 \%$ of the cases. In 1988, Kakou et al ${ }^{28}$ presented the results of the study of 21 patients, reporting an increase in early mortality due to delayed surgery.

In spite of the lack of investigations with large numbers of patients, the national experience is relevant and noteworthy. The first surgical case appears to have been reported in $1976^{29}$. Subsequently, case reports emphasizing specific aspects such as surgical technique ${ }^{30}$, presentation in adult life ${ }^{31}$, benefits of early surgery ${ }^{32}$, atypical origin of LCA from the pulmonary artery branches ${ }^{17}$, and simultaneous mitral surgery and correction of AOLCA ${ }^{33}$ have been gradually documented. More recently, the simultaneous occurrence of stroke ${ }^{34}$ and mitral valve replacement ${ }^{35}$ was reported in 2 patients who received aortic reimplantation of the LCA.

The material of this study represents a successful experience with 11 patients operated upon early ( 9 infants) or at the time the diagnosis was established ( 2 children). With regard to preoperative data, it is interesting to note that 2 of our patients showed late clinical findings, with few symptoms and slightly abnormal ECG. This is not common in this condition. In spite of the difficulty in diagnosing angina, this finding (55\%), as well as a systolic mitral murmur $(88 \%)$, were common, as previously described ${ }^{12}$. The ECG is a well-known valuable element in the diagnosis of AOLCA. In our cases, the marked incidence of left electric axis deviation (64\%), the pattern of ischemia/necrosis in infants $(100 \%)$ and the presence of a deep Q wave in lead AVL $(91 \%)$ are important findings with regard to the diagnostic suspicion. The absence of $Q$ wave in the lower leads, recently descri-bed as a relevant diagnostic criterion ${ }^{36}$, was also often noted in our patients $(82 \%)$. It must be remembered that atypical electrocardiographic findings may mask this disease when it is associated with lesions causing significant increase in pulmonary flow ${ }^{13,14}$. Anomalous LCA is usually detected by echocardiography (64\% of our cases), and the left ventricular function is often significantly impaired. The hemodynamic study may occasionally be necessary in order to diagnose the disease or confirm the echocardiographic findings, as occurred with 7 of our patients in the beginning of our experience.

The surgical treatment of this anomaly brings unquestionable benefits and, in recent years, a wide array of reports were published on these surgical approaches ${ }^{2,27,28,37-40}$. The importance of early surgical intervention is well documented, and its objective is to interrupt the development of myocardial damage. All the infants in our study were operated upon during the first year of life (eight were operated upon between the $2^{\text {nd }}$ and $6^{\text {th }}$ month of life), and none of them died. The origin of anomalous LCA from the pulmonary trunk is usually located in the left posterior wall. This was supported in our study and also in the study by Moraes et $\mathrm{al}^{2}$, which 
includes some of our patients. With regard to the technique employed for the correction of this anomaly, the aortic implantation of the LCA seems a very logical approach and it was performed in 6 of our patients. Recently, a technical detail was des-cribed ${ }^{41}$, which may facilitate the use of this technique. Attention must be paid to the potential development of immediate postoperative complications, mainly the persistence of low cardiac output. This occurred in 4 of our patients and can usually be managed by an intensive postoperative therapy.

The surgical approach provides encouraging results. We consider noteworthy the fact that 8 of the 9 infants in our study were asymptomatic during the last outpatient visit. This is probably related to the fact that surgery was performed early in the disease, allowing a faster myocardial recovery. Focus has been given to the importance of early surgical intervention ${ }^{37}$. Sauer et al ${ }^{42}$ considered that an early age at the time of the surgery constitutes an important risk factor. This fact must not be valued. The benefits of the surgical approach include, in addition to an increase in survival, the disappearance or marked improvement of the ischemia/necrosis pattern in all the infants in our study, although some slight abnormalities were still present in the ECG tracings.

In regard to the need of an additional surgery, we found that the 6 patients who received aortic implantation of LCA did not require a second surgical intervention. However, among the 5 patients operated upon according to the Takeuchi technique, 2 were precociously reoperated upon due to the presence of severe pulmonary supravalvular stenosis, and 2 additional patients showed a $20 \mathrm{mmHg}$ gradient across the right ventricular outflow tract. In spite of this small number of patients, we believe that the direct aortic implantation of the LCA should be the procedure of choice. Although, in some cases, this technique may be difficult to perform ${ }^{43}$, other authors believe that this is a viable procedure in any case ${ }^{2,28}$.

The left ventricular function, usually assessed by the echocardiogram, is another important aspect to be considered during the follow-up of these patients after surgery. An interesting study recently published shows that, in spite of the presence of electrocardiographic abnormalities, the exercise performance tends to be preserved, as shown by a negative thallium scintigraphy ${ }^{44}$. Carvalho et al ${ }^{45}$ found, in a detailed echocardiographic study, that the global ventricular function returned to normal levels after surgery, a finding that seems to be common in these cases. Bunton ${ }^{40}$ and, more recently, Jin ${ }^{46}$, also documented these findings. In spite of these optimistic data, new techniques such as scintigraphy under dipyridamole stress ${ }^{47}$ and dobutamine stress echocardiography ${ }^{48}$ have been consi- dered useful in the detection of myocardial perfusion and contraction abnormalities. However, more detailed studies are needed to confirm these findings.

Little has been discussed about mitral valve function after surgery. Some reports try to relate the impaired function of this valve before surgery with a poor outcome after surgery ${ }^{49}$. During late follow-up, as described ${ }^{50}$, some patients may show severe mitral regurgitation secondary to preoperative ischemia, occasionally requiring valvular replacement.

In conclusion, we would like to confirm that AOLCA is a rare anomaly and that these patients tend to show early clinical findings, such as heart failure and marked electrocardiographic abnormalities. The echocardiogram usually establishes the diagnosis; however, hemodynamic studies may be required. In spite of the small sample size of our study, aortic implantation of the LCA seems to be a viable approach and should be the procedure of choice. Takeuchi's surgery should be the second option and the possibility of an obstruction of the right ventricular outflow tract must be remembered. Surgery must be performed early, aiming to preserve myocardial function, which tends to return to normal levels after surgery in the short-term. We believe that additional studies of this anomaly should focus on the surgical results of a larger number of patients in order to confirm the possibility of achieving very favorable outcomes, such as those presented here. The actual incidence of pulmonary supravalvular stenosis after Takeuchi's surgery, as well as the left ventricular function in adult life, must be determined.

Limitations of this study - The sample studied is not representative of the overall experience of the institution. However, the information obtained during the data collection period shows the probable occurrence of 2 or 3 additional cases, thus completing the whole sample. The electrocardiographic documentation is not optimal because only copies of the electrocardiographic tracings were available. We believe, however, that ECG analysis could be performed without impairing the conclusion. The echocardiographic evaluation of the left ventricular function is incomplete due to the absence of these values in the exams obtained. The study tended to value primarily the qualitative aspect of the contractility of the left ventricle.

\section{Acknowledgments}

To Dr Darryl Shore, a cardiovascular surgeon, for his permission to study his operated patients. 


\section{Referências}

1. Keith JD - The anomalous origin of the left coronary artery from the pulmonary artery. Br Heart J 1959; 21: 149-61.

2. Moraes F, Lincoln C - Anomalous origin of left coronary artery. Evolution of surgical treatment. Eur J Cardiothorac Surg 1996; 10: 603-8.

3. Wesselhoef H, Fawcett JS, Johnson AL - Anomalous origin of the left coronary artery from the pulmonary trunk: its clinical spectrum, pathology and pathophysiology based on a review of 140 cases with seven further cases. Circulation 1968; 38: 403-25.

4. BackerCC, Stout MJ,Zales VR, et al - Anomalous origin of the left coronary artery: twenty-year review of surgical management. J Thorac Cardiovasc Surg 1992; 103 : 1049-58.

5. Neches WH, Mathews RA, Park SC, et al - Anomalous origin of the left coronary artery from the pulmonary artery. Circulation 1974; 50: 582-7.

6. Grace RR, Angelini P, Cooley DA - Aortic implantation of anomalous left coronary artery arising from pulmonary artery. Am J Cardiol 1977; 39: 608-13.

7. Takeuchi S, Imamura H, Katsumoto K, et al - New surgical method for repair of anomalous left coronary artery from pulmonary artery. J Thorac Cardiovasc Surg 1979; 78: 7-11.

8. Sans-Coma V, Argué JM, Durán AC, Cardo M-Origin of the left main coronary artery from the pulmonary trunk in the syrian hamster. Am J Cardiol 1988; 62: 159-61.

9. Krause W - Uber den ursprung einer accessorischen a. coronaria cordis aus der a. pulmonalis. Z Rat Med 1865; 24: 225.

10. Brooks HSJ - Two cases of abnormal coronary artery arising from the pulmonary artery. J Anat Physiol 1886; 20: 26-32.

11. Abrikossoff A - Aneurysm des liuken herzventrikels mit abnormer abrangstelle der linken koronarterie von der pulmonalis bei einem funfmonatlichen kinde. Virchows Arch 1911; 203: 413.

12. Bland EF, White PD, Garland J - Congenital anomalies of the coronary arteries: report of an unusual case associated with cardiac hypertrophy. Am Heart J 1933; 8 : 787-801.

13. Nakagawa M, Kimura K, Watanabe $\mathrm{Y}$ - Atypical electrocardiogram and echocardiogram in a patient with Bland-White-Garland syndrome in association with atrial septal defect. Cardiology 1996; 87: 358-60.

14. Sreeram N, Hunter S, Wren C-Acute myocardial infarction in infancy: unmasking of anomalous origin of the left coronary artery from the pulmonary artery by ligation of an arterial duct. Br Heart J 1989; 61: 307-8.

15. Levin SE, Dansky R, Kinsley RH - Origin of left coronary artery from right pulmonary artery co-existing with coarctation of the aorta. Int J Cardiol 1990; 27: 31-6

16. incent RN, Rastegar DA, Dhar P, Kanter KR - Anomalous origin of the left coronary artery from the pulmonary artery associated with ventricular septal defect and mitral stenosis. Pediatr Cardiol 1997; 18: 315-7.

17. Atik E, Barbero-Marcial M, Ikari NM, et al - Origem da artéria coronária esquerda das artérias pulmonares, direita e esquerda. Avaliação clínica, anatomopatológica e evolutiva de três casos. Arq Bras Cardiol 1991; 57: 121-7.

18. Edwards JE - The direction of blood flow in coronary artery arising from the pulmonary trunk. Circulation 1964; 29: 163-6.

19. Shivalkar B, Borgers M, Daenen W, Gewillig M, Flameng W - ALCAPA syndrome: an example of chronic myocardial hypoperfusion? J Am Coll Cardiol 1994; 23: 772-8.

20. Serraf A, Baron O, Nottin R, et al - Atresie ou stenose congenitale de l'ostium coronaire gauche. Revascularisation myocardique chez 5 enfants. Arch Mal Coeur Vaiss 1993; 86: 587-91.

21. Hayashi Y - A case of Bland-White-Garland syndrome with myocardial infarction on the first day after birth. Pediatr Cardiol 1990; 11: 175-6.

22. Sabiston Jr DC, Neil CA, Taussig HB - The direction of blood flow in anomalous left coronary artery arising from the pulmonary artery. Circulation 1960; 22: 591-7.

23. Cooley DA, Hallman CL, Bloodwell RD - Definitive surgical treatment of anomalous origin of left coronary artery from pulmonary artery: indications and results. J Thorac Cardiovasc Surg 1966; 52: 798-808.

24. McNamara DG, El-Said G - Treatment of anomalous origin of the left coronary artery from the pulmonary artery. Eur J Cardiol 1973; $1: 497$.

25. Meyer BW, Stefanik G, Stiles QR, Lindesmith GG, Jones JC - A method of definitive surgical treatment of anomalous origin of left coronary artery: a case report. J Thorac Cardiovasc Surg 1968; 56: 104-7.

26. Vigneswaran WT, Campbell DN, Pappas G, Wiggins JW, Wolfe RW, Clarke DR Evolution of the management of anomalous left coronary artery: a new surgical approach. Ann Thorac Surg 1989; 48: 560-4.

27. Lambert V, Touchot A, Losay J, et al - Midterm results after surgical repair of the anomalous origin of the left coronary artery. Circulation 1996; 94 (suppl): 38-43.
28. Guikahue MK, Sidi D, Kachaner J, et al - Anomalous left coronary artery arising from the pulmonary artery in infancy: is early operation better? Br Heart J 1988; 60: 522-6.

29. Oliveira SA, Santana $\mathrm{F}^{\circ}$ GP, Ebaid M, Macruz R, Ariê S, Zerbini EJ - Artéria coronária esquerda com origem na artéria pulmonar. Tratamento cirúrgico. Rev Bras Med 1976; 33: 8-

30. Wanderley Neto J, Torres D, De Biase A, et al - Tratamento cirúrgico da origem anômala da coronária esquerda da artéria pulmonar. Nova técnica e relato de caso. Arq Bras Cardiol 1985; 44: 45-8.

31. Mansur AP, Ramires JAF, Oliveira SF, Favarato D - Angina de esforço em paciente adulto com origem anômala de artéria coronária esquerda. Arq Bras Cardiol 1990; 55: 43-5.

32. Almeida SL, Mazzieri R, Berlinck MF, Souza JM, Oliveira SA - Correção cirúrgica precoce da artéria coronária esquerda com origem em tronco pulmonar. Evolução tardia. Arq Bras Cardiol 1990; 55: 319-23.

33. Ikari NM, Diógenes TCP, Gutierrez PS, et al - Disfunção da valva mitral por necrose de músculo papilar em origem anômala de artéria coronária esquerda do tronco pulmonar. Arq Bras Cardiol 1991; 57: 129-32.

34. Carvalho ACC, Lima JF, Soares ACC, et al - Acidente vascular cerebral em criança portadora de origem anômala da artéria coronária esquerda. Arq Bras Cardiol 1994; 63: 117-9.

35. Echeverria NMG, Atik E, Ikari NM, Riso A, Barbero-Marcial M, Ebaid M Origem anômala da artéria coronária esquerda. Correção concomitante à substituição valvar por insuficiencia mitral. Arq Bras Cardiol 1995; 65: 335-7.

36. Johnsrude CL, Perry JC, Cecchin F, et al - Differentiating anomalous left main coronary artery originating from the pulmonary artery in infants from myocarditis and dilated cardiomyopathy by electrocardiogram. Am J Cardiol 1995; 75: 71-4

37. Wolleneck G, Domanig E, Salzer-Muhar U, Havel M, Wimmer M, Wolner E Anomalous origin of the left coronary artery: a review of surgical management in 13 patients. J Cardiovasc Surg 1993; 34: 399-405.

38. Backer CL, Stout MJ, Zales VR, et al - Anomalous origin of the left coronary artery. A twenty-year review of surgical management. J Thorac Cardiovasc Surg 1992; 103: 1049-57.

39. Tiraboshi R, Manasse E, Borghi A, Brunelli F, Parenzan L - Anomalous origin of the left coronary artery from the pulmonary artery. Experience with 13 cases. $\mathrm{J}$ Cardiovasc Surg 1988; 29: 335-8

40. Bunton R, Jonas RA, Lang P, Rein AJ, Castaneda AR - Anomalous left coronary artery from the pulmonary artery. Ligation versus establishment of a two coronary system. J Thorac Cardiovasc Surg 1987; 93; 103-8.

41. Laks H, Ardehali A, Grant PW, Allada V - Aortic implantation of anomalous left coronary artery. An improved surgical approach. J Thorac Cardiovasc Surg 1995; 109: 519-23.

42. Sauer U, Stern H, Meisner H, Buhlmeyer K, Sebehing F - Risk factors for perioperative mortality in children with anomalous left coronary artery from the pulmonary artery. J Thorac Cardiovasc Surg 1991; 104: 696-705.

43. Raanani E, Abramov D, Abramov Y, Birk E, Vidne BA - Individual anatomy demands various techniques in correction of an anomalous origin of the left coronary artery in the pulmonary artery. Thorac Cardiovasc Surg 1995; 43: 99-103.

44. Paridon SM, Farooki ZQ, Kuhns LR, Arciniegas E, Pinsky WW - Exercise performance after repair of anomalous origin of the left coronary artery from the pulmonary artery. Circulation 1990; 81: 1287-92.

45. Carvalho JS, Redington AN, Oldershaw PJ, Shinebourne EA, Lincoln CR, Gibson DG - Analysis of left ventricular wall movement before and after reimplantation of anomalous left coronary artery in infancy. Br Heart J 1991; 65: 218-22.

46. Jin F, Berger F, Unlemann F, et al - Improvement in left ventricular dysfunction after aortic reimplantation in 11 consecutive pediatric patients with anomalous origin of the left coronary artery from the pulmonary artery. Early results of a serial echocardiographic study. Eur Heart J 1994; 15: 1044-9.

47. Stern H, Sauer U, Locher D, et al - Left ventricular function assessed with echocardiography and myocardial perfusion assessed with cintigraphy under dypiridamole stress in pediatric patients after repair for anomalous origin of the left coronary artery from the pulmonary artery. J Thorac Cardiovasc Surg 1993; 106: 723-32.

48. Leal SM, Carvalho AC, Mathias W, Arruda AM, Andrade JL - Dobutamine stress echocardiography in anomalous left coronary artery. Pediatr Cardiol 1998; 19: 178-81.

49 Schwartz ML, Jonas RA, Colan SD - Anomalous origin of left coronary artery from pulmonary artery: recovery of left ventricular function after dual coronary repair. 